Diseases of the oesophagus. Pathophysiology, diagnosis, conservative and surgical treatment. Edited by J R Siewert and A H Holscher. (Pp. 1400; illustrated; DM 398.) Berlin: Springer-Verlag, 1988.

This book of 1400 pages represents the information presented to the International Society for Diseases of the Esophagus (ISDE) third triennial congress in Munich in September 1986. The next conference will be in Chicago in September 1989. There were 700 participants and most of the 380 presentations have been included. The meeting combined with three other groups - the International Conference of Esophageal Diseases, the European Study Group of Diseases of the Esophagus (GEEMO) and the International organisation for Statistical Studies of Esophageal Diseases (OESO) - in an attempt to unify the different meetings, avoid duplication or triplication and promote international cooperation. The resultant book is not a hotch-potch of data, but represents the efforts of the organisers of a superb meeting to systemerise the presentations to provide an overall picture of the present state of information on the oesophagus. The book is impeccably published with clear type, figures, and a good index.

Of special mention is the chapter by Iizuka on TNM classification for oesophageal cancer. Based on the huge and accurate data base in Japan they propose changes in the classification because the survival rates for the different staging which result from this new TNM classification are meaningfully different. This implies that data are collected for a practical purpose. It is equally apparent that the results of treatment depend more on the initial staging than the type of operation or management, but no clear answers appear as to how oesophageal cancer should be treated.

There are 50 pages on columnar cell lined oesophagus which is still called Barrett's oesophagus (he did not know the cause, nor do we) and that false neologism endobrachyoesophagus (is in columnar cell lined not 'endo' and 'brachy' presumably implies a short oesophagus which it is not). No clear message comes as to whether it should be treated, is it premalignant and does it progress to stricture formation or whether we should bother to diagnose it.

Cost benefit analysis has appeared quite correctly and Donner estimates the costs of working up a patient with gastroesophageal disease in USA as $\$ 233$ for dynamic radiology, $\$ 525$ for endoscopy, $\$ 200$ for manometry and $\$ 257$ for $24 \mathrm{~h} \mathrm{pH}$ monitoring. If the medical profession does not consider the expenses, somebody else will, and here is a start.

This book contains many more interesting chapters and it will repay the expert to sift through and read it. Repay is probably the wrong word as it costs $398 \mathrm{DM}$ or about $£ 125$, but that could be deducted from the price of the next endoscopy. It weighs $2453 \mathrm{~g}$, the publishers say, so there is no need to be on anabolic steroids to hold in on your knee, but how heavy will the proceedings of the next meeting be and how much will we learn? There is considerable information in this excellent book but how much knowledge? Knowledge is usually short and succinct; most brains, like computers, have a limit on data storage.

RICHARD EARLAM

Gastroesophageal reflux. By G G Jamieson and A Duranceau. (Pp. 281; illustrated; £31.) Philadelphia: W B Saunders, 1988.

Gastro-oesophageal reflux is in fashion, not least because the pharmaceutical industry has discovered it as the commonest identifiable cause of chronic dyspepsia, so a review of the subject is opportune. The authors planned 'a text that should remain a solid reference over the years', and so it is-plenty of references, but all too solid; the enthusiasm for a complete historical account leads to dreariness and sometimes displaces a sharper, more incisive critique of the evidence. Although the contribution of surgeons to knowledge in this field is valuable and honourable, it seems unbalanced that this book's contributors are 10 surgeons and a paediatrician. One result is a simplistic account of medical therapy in nine pages compared with 35 on antireflux surgery.

The editors rightly see a need for greater clarity and uniformity in methodological description of investigations, and offer their own ideas, some of which could be widely adopted with advantage, others requiring further refinement.

Like many books this must have been a long time in the making, so some chapters are more up-to-date than others (one refers to 'recent' work, dated 1982). There was no mention of the work of Orlando on mucosal resistance, or of Cameron's epidemiological study of malignancy in the columnar lined gullet, and only passing reference to the Milwaukee clarifications of saliva's role in 'clearing'.

Overall this is a sound and useful review of the topic, but you should read it quickly before it reaches its 'best by' date.

J R BENNETT

Disorders of gastrointestinal motility in childhood. Edited by P J Milla. (Pp. 143; illustrated; £21.95.) Chichester: Wiley, 1988.

Peter Milla and his collaborators at the Institute of Child Health in London are the pioneers of research into enteric motility in infants. Their work is all the more remarkable because their hospital in Great Ormond Street has no obstetric unit to ensure a steady supply of neonates. Milla has recruited contri- 
butors from other institutions to provide a balanced picture of childhood motility disorders, and their diagnosis and management. The emphasis is on infancy, but that is only to be expected; for the most part, children are born with these disorders and it is only to be expected that they will be diagnosed in early life. The chapters vary in scope from reviews to accounts of single research projects, but this is the state of the art in this field, and (almost) none of the chapters are dull. The only discordant note in the book is a chapter on 'pro-kinetic drugs' by two authors from the 'Janssen Research Foundation'. Half of the chapter is devoted to the discussion of two drugs (one not yet licensed in the USA, the other neither in the UK nor the USA) that, by an amazing coincidence, are manufactured by a pharmaceutical company that shares the name and address of the research foundation. Perhaps a firmer editorial hand was needed here. ...

This is a slim volume, but like its topic, the subject is relatively infant. It is the more unfortunate that the price of the book is precociously mature; one can only hope that this will not deter both paediatricians and gastroenterologists from buying this book.

\section{DAVID WINGATE}

Nutrition and immunology - Contemporary issues in clinical nutrition II. Edited by R K Chandra. (Pp. 352; illustrated; \$96.) New York: Liss Inc, 1988.

The connection between nutrition and immunology is a fascinating one and is of special interest, particularly to developing countries. It is certainly not exaggerated that malnutrition is the major cause of secondary immune deficiencies in the world, as stated in the introduction to this volume. As one reads on it becomes obvious that one major problem in elucidating the role of nutrition on the immune system is the fact that most studies are done in children with protein calorie malnutrition - usually with infections - where there is not a deficiency of only one nutrient. The effects of single nutrient deficiencies are mostly investigated in animal studies where the extrapolation to human conditions is only possible with great caution. Based on this background, the book is timely and 19 authors have reviewed the world literature and tried to separate fact from fiction in this difficult area of research. The balance of this book is slightly tipped to the nutritional side, and only three authors are-by their affiliation-identifiable as immunologists. The effects of under nutrition on cytokine responses and on plasma inhibitory factors are covered as well as the effects of lipid disurbances, vitamins, iron, zinc and other trace element deficiencies. I believe, as a personal hobby of the editor, the effects of over nutrition are also covered. Although the book is well edited, it is not quite clear to me how 'Immunoparesis caused by viral and bacterial infections' and 'Immunological aspects and diabetes mellitus' fit into this worthwhile volume. I personally liked the chapters on lipids, vitamin B and iron deficiency best; they were well structured, well referenced and critically assessed.

This book is certainly valuable for $\mathrm{PhD}$ students embarking on research in this field. It is less rewarding for 'pure' immunologists who would have liked a more thorough and critical discussion of the immunological results presented. It is also of interest for paediatricians intending to work in developing countries or looking after children with chronic malabsorptive states.

The price of $\$ 69$ probably makes it out of reach for the interested individual, but the money is certainly well spent for departmental and/or institute libraries.

STEPHAN STROBEI

\section{Books received}

Gastrointestinal and hepatobiliary physiology diagnosis and treatment. Edited by $\mathrm{J}$ Picazo. (Pp. 175; illustrated; $£ 30 \cdot 00$.) Lancaster: MTP Press Ltd, 1987.

Vasopressin analogs and portal hypertension. Edited by D Lebrec and A T Blei. (Pp. 174; illustrated; no price stated.) Paris: John Libbey Eurotexts, 1987.

Animal models of portal hypertension. Edited by $\mathrm{S} \mathrm{K}$ Sarin and N C Nayak. (141; illustrated; Rs. 200/-.) New Delhi: King Publishing House, 1988.

Advances in internal medicine, $\mathrm{Vol} 33$. Edited by $\mathrm{G} \mathrm{H}$ Stollerman et al. (Pp. 542; illustrated; £45.50.) Chicago: Year Book Medical Publishers, 1988.

Gut regulatory peptides: their role in health and disease. Edited by E Blazquez. (Pp. 236; illustrated; £84-10.) Basel: S Karger A G, 1987.

Spondyloarthropathies: involvement of the gut. Edited by $\mathrm{H}$ Mielants and $\mathrm{E} M$ Veys. (Pp. 456; illustrated; Dfl. 275.00.) Amsterdam: Elsevier Scientific Publishers, 1987.

Key developments in gastroenterology. Edited by $\mathrm{P} R$ Salmon. (Pp. 194; illustrated; £26-50.) Chichester: John Wiley, 1988.

Cellular calcium and phosphate transport in health and disease. Edited by F Bonner and M Peterlik. (Pp. 448; illustrated; \$78.00.) New York: Alan R Liss, Inc, 1988. 